\title{
Moderate/high resistance exercise is better to reduce blood glucose and blood pressure in middle-aged diabetic subjects
}

http://dx.doi.org/10.11606/1807-5509202000010165

\section{Abstract}

Type 2 diabetes (T2D) main feature is insulin resistance. Hypertension is a comorbidity linked to T2D. Resistance exercise (RE) is an important non-pharmacological tool to contribute to managing blood glucose and blood pressure (BP), but there is not a common sense about acute effects. The aim of this study was to evaluate the acute physiological effects after two different RE sessions using different intensities at middle-aged hypertensive T2D subjects. There were 40 middle-aged men $(20$ nondiabetics; 20 diabetics), who underwent an exercise protocol with the same volume at $60 \%$ or $75 \%$ of the one maximum repetition test (1RM), consisting in: bench press, triceps pulley, rowing machine, barbell curl, lateral raise with dumbbells and barbell squat. Physiological changes were evaluated through $\mathrm{BP}$, glycemia, creatine kinase, lactate dehydrogenase, $C$ reactive protein (C-RP), testosterone and cortisol. For non-diabetics, both intensities promoted blood glucose uptake $(8.2 \%$ to $11.1 \%, p<0.05)$, and only the 75\%1RM session induced blood glucose uptake in 5.7\% in the diabetics. Post-exercise hypotension was significant after RE at 75\%1RM for systolic BP (SBP) and after both intensities for diastolic BP (DBP) in non-diabetics, while the SBP and DPB reduced after both intensities for diabetics. RE at 75\%1RM resulted in better blood glucose uptake, and both intensities reduced the BP in diabetic subjects. After 75\%1RM there was a higher indirect muscle damage result. The alterations in hormones, C-RP, and indirect muscle damage markers indicated an adequate acute anabolic recovery with no significant inflammation in both intensities. Acute RE at 60\%1RM or 75\%1RM can used as an extra tool to manage both pathologic conditions.

KeYwords: Type 2 Diabetes Mellitus; Hypertension; Resistance Exercise; Health.

\section{Introduction}

There are different types of diabetes, but type 2 diabetes mellitus (T2D) is the most common, affecting $95 \%$ of subjects with diabetes worldwide ${ }^{1}$. T2D main characteristic is insulin resistance and presents two clinical outcomes: hyperglycemia and hyperinsulinemia ${ }^{2}$. Diabetes can lead to different types of comorbidities such as hypertension. At least $70 \%$ of individuals with T2D have uncontrolled hypertension or have been treated for elevated blood pressure $(\mathrm{BP})^{3}$. The maintenance of BP within the normal level is important in order to not only promote greater and better control of hypertension but also of the blood glucose levels and physical exercise is an essential tool to make it happen ${ }^{4}$. The absence or low practice of physical exercise, as well as a sedentary lifestyle, can contribute to the development of T2D and hypertension ${ }^{2,5}$.

Physical exercise can induce post-exercise hypotension $(\mathrm{PEH})$ and reduce glycemic level, especially during the first $24 \mathrm{~h}^{6,7}$. Thus, aerobic exercise is usually recommended in T2D and hypertension, but resistance exercise (RE) can also induce physiological benefits ${ }^{6}$. RE movements are interspaced, and the muscle contraction is executed by a particular muscle 
or a muscle group which is opposed to a force, and sometimes, is against to the movement ${ }^{6,8}$.

Physiological alterations are observed in RE such as muscle damage and hormonal changes immediately after RE. Creatine kinase (CK) and lactate dehydrogenase (LDH) increase are wellknown indirect muscle damage markers and are important tools to define the effectiveness of the physical training. The high concentration differences in pre and post-workout for CK and $\mathrm{LDH}$ are the basis of muscle damage and $C$ reactive protein (C-RP) can be used as a complementary marker to determine if the damage is harmless or not ${ }^{9}$.

Hormonal changes are also part of the physiological changes during and immediately after RE sessions. Testosterone levels are usually reduced in T2D. Changes in testosterone levels can influence insulin sensitivity, amplifying or not the glucose uptake and its transport to different tissues ${ }^{10}$. Alterations in the levels of cortisol can induce modifications in the recruitment of different types of muscular fibers during $\mathrm{RE}$ and may contribute to loss of muscle mass (sarcopenia), and to the reduction of muscular strength (dynapenia) ${ }^{11}$. Positive change in the testosterone and cortisol ratio ( $\mathrm{T}: \mathrm{C})$ indicates a good physiological recovery and represents the relation between anabolic and catabolic systems.
Low $\mathrm{T}: \mathrm{C}$ ratio may indicate the beginning of the development of insulin resistance, obesity, and cardiovascular dysfunction ${ }^{10}$.

It has been shown ${ }^{12}$ that the blood glucose control obtained with the use of chronic highintense $\mathrm{RE}$ is more effective in controlling glycemia levels than the moderate and light RE. However, moderate exercise intensity, in a chronic model, is more indicated for safety reasons ${ }^{13}$ to groups with a history of diabetes and hypertension, as recommended by American College of Sports Medicine and American Heart Association ${ }^{14}$.

The moderate RE is performed at any intensity between $60 \%$ and $80 \%$ of the maximum weight workload carried out by an individual ${ }^{15}$, however, it is not clear in which percentage of the maximum intensity, lower or higher, the moderate RE would provide a better acute physiological response when performed by hypertensive T2D individuals. The confirmation of changes in physiological results after different moderate intensities of RE to this population can lead to advances in the prescription and evaluation of physical exercise training.

The aim of this study was to evaluate the acute effects of two different moderate RE intensities on the glycemia, blood pressure and markers of stress and muscle damage at middle-aged hypertensive type 2 diabetic subjects.

\section{Method}

The National Committee for Ethics in Research and the Ethics Committee of the Federal University of Sergipe approved this study under protocol 387.704. All participants signed a consent form authorizing the participation and the use of the data collected in this study, according to Resolution 466/12 of the National Health Council of Brazil and followed the Declaration of Helsinki.

\section{Subjects}

The sample was composed of 40 male volunteers. There were initially two groups: nondiabetics (ND; control group) and hypertensive diabetics (D), who were later subdivided into 4 groups, consisting of 10 individuals each, separated according to the percentage of the maximum intensity session. The groups performed the RE protocols at 60\% (ND60 and D60) or at 75\% (ND75, and D75) of the 1 repetition maximum test (1RM). The main features of the groups are shown in TABLE 1. These intensities are moderate and they were chosen due safety reasons, being $60 \%$ of $1 \mathrm{RM}$ closer to lowest moderate exercise zone, and 75\% of $1 \mathrm{RM}$ is still moderate zone, closer to $80 \%$ of $1 \mathrm{RM}$, considered the threshold zone between moderate and intense zone ${ }^{16}$.

The including criteria adopted to participate in the exercise protocol was: to be a male between 40 and 60 years old, and could not be doing regular physical activity during the last six months was a must. It was not considered regular 
physical activity if the exercise or sport was performed less than 3 times a week in a shorter period than 30 minutes ${ }^{13}$. Diabetic hypertensive volunteers included in the study had the disease diagnosed clinically by a physician for at least one year and the glucose levels and blood pressure controlled by diet and/or medication. It would be excluded from the study anyone who was making use of exogenous insulin, or if they had chronic complications such as cardiovascular disease (excluding hypertension), diabetic foot, retinopathy, neuropathy, and nephropathy ${ }^{6}$.

An individualized breakfast was suggested to all participants of the experimental protocol. This procedure was adopted because a rich breakfast in fats or carbohydrates may influence the blood glucose level at pre- and post-exercise protocol. Water was freely consumed before and after the procedure. All procedures were conducted by the same professional at all times.

\section{Exercise Sessions}

One week prior to the $1 \mathrm{RM}$, there was a habituation session where the participants had contact with the exercises they would perform and execute them without weights. The 1RM test was performed to establish the weight load of two moderate RE intensities used during exercise sessions. 1RM consisted of one single repetition using the maximum of the weight load that can lifted during the execution of a specific exercise. It was performed with alternation between the concentric and eccentric phases taking 2 s for each phase $^{17}$. After the first trial, participants had a passive interval of $180 \mathrm{~s}$. When the execution of the movement was successful, $10 \%$ of the work load used was added, and in case of failure, 10\% was removed by the weight used. A maximum of 3 attempts, increasing or decreasing the load, was established to determine the maximal strength.

Each group performed a single session of the exercise protocol. After the resting period, stretches were performed for 5 minutes to the upper limb. Right after the stretching period, the subjects performed a warm-up for the main muscle groups of their body (chest, back, and legs) using two series with the minimum weight on the machines and barbells, executing 20 repetitions of specific exercises for these muscle groups (described in the experimental protocol below). The interval between sets was 45 seconds.
Five minutes after the warm-up the test protocol was initiated.

The experimental protocol was performed 72 hours after the 1RM test for each group. All subjects performed the RE session just once and the four groups executed the same exercise sequence, with intensities at $75 \%$ or $60 \%$ of 1RM. All sessions were performed consisting of 3 sets of 10 repetitions each. The resting time between sets was 1 minute ${ }^{13}$ and the rate of contraction of the exercise was $2 s$ for the concentric phase and $2 \mathrm{~s}$ for the eccentric ${ }^{18}$.

Exercises used for all groups were an attempt to portray a traditional session for beginners at gyms, consisting of 6 exercises and working out the main muscular groups. The exercises chosen to be performed were: bench press, triceps pulley, rowing machine, barbell curl, lateral raise with dumbbells and barbell squat, and always in the same order for all participants. It is important to highlight that the $1 \mathrm{RM}$ was performed in each of these six exercises. The total volume was calculated to each intensity of RE from the sum the results of the multiplication of the load of each exercise by repetitions and series.

\section{Pre- and post-exercise procedures}

Blood pressure and heart rate were measured before and $1 \mathrm{~h}$ after the exercise session by an oscillometric tensiometer (branch Omron, automatic arm equipment, Hem 7200 model). The $\mathrm{BP}$ was measured on the left arm of the participants that were keeping in a seated position.

Blood capillary samples from fingers were collected and placed in tapes to evaluate glycemia (Acku-Check Advantage), as well as blood samples, were collected by antecubital vein for $4 \mathrm{ml}$ per tube from each subject. Blood samples collections occurred between 7:00 and 9:00 am, before experimental protocols and 10 minutes after exercise sessions to analyze glycemia, as well as, CK, LDH, C-RP, testosterone, and cortisol.

When the systolic and/or diastolic blood pressure and/or glycemia presented values $\geq 180$ $\mathrm{mmHg}$ and/or $105 \mathrm{mmHg}^{19}$ and/or $\leq 100 \mathrm{mg} /$ $\mathrm{dL}$ or $\geq 300 \mathrm{mg} / \mathrm{dL}^{20}$, the experimental session was rescheduled, and the volunteer was aimed at finding a basic health unit. These situations did not occur.

$\mathrm{CK}$ and $\mathrm{LDH}$ were measured in the plasma, through the kinetic colorimetric method at 
multiple time points 9 . The method used to dosage of the C-RP was the high sensitivity turbidimetry ${ }^{21}$. C-RP analysis was performed in an automatic spectrophotometer and when "positive", it was considered as an inflammatory zone. Testosterone and cortisol analyses were performed through chemiluminescence method. Blood samples were centrifuged for $10 \mathrm{~min}$ at $3000 \mathrm{rpm}$ and an automatic biochemical analyzer was used. Bio Advance Kits were used during the dosages. The $\mathrm{T}$ : $\mathrm{C}$ ratio was obtained by dividing the testosterone concentrations by cortisol concentrations.

Disposable syringes and materials were used in all samples collected by the same professional at all times. One Huma Star 300 spectrophotometer,
Human brand, was used for biochemical analyses. A centrifugal of the CELM brand model was also used.

\section{Statistical Analyses}

Mean and standard deviation (SD) were used for statistical analysis. Normality of the data was evaluated through Shapiro-Wilk test. Analysis of variance (ANOVA) for repeated measures between the four groups and two moments (with a syntax of $4 \times 2$ ) with multiple's pairs comparisons of Bonferroni was applied for glycemia, BP, testosterone, cortisol, CK, and $\mathrm{LDH}$. The significance level was set at 5\% $(\mathrm{p}<0.05)$, and all analysis were carried out using the SPSS 15.0 version.

\section{Results}

TABLE 1 shown the rest values for different variables in the present study, divided between nondiabetic (ND) and diabetic (D) groups in each RE intensity. Only heart rate, testosterone, cortisol, CK and LDH levels did not differ between groups. All three sets were completed for all volunteers in all attempts.

The total volume of the exercise sessions was not differ between groups and RE intensities (ND60: $20952 \pm 6603$; ND75: $22680 \pm 7500 ;$ D60: 21168 \pm 6891; D75: $22896 \pm 5778, \mathrm{p}>0.05)$.

Glycemia was reduced $(\mathrm{p}<0.05)$ after $\mathrm{RE}$ at
$60 \%$ and $75 \% 1 \mathrm{RM}$ for nondiabetic groups ( $8.2 \%$ and $11.1 \%$, respectively), however only $\mathrm{RE}$ at $75 \% 1 \mathrm{RM}$ resulted in significant reduction of $5.7 \%$ on glycemia level in the diabetic group (FIGURE 1A).

After exercise protocols, significant reductions $(\mathrm{p} \leq 0.05)$ were observed for SBP to ND75, D60, and D75 (FIGURE 1B), and for DBP to ND and $\mathrm{D}$ groups (FIGURE 1C). The RE at $75 \%$ $1 \mathrm{RM}$ revealed a better reduction for $\mathrm{SBP}$ and DBP for ND and D groups, especially for ND group $(\mathrm{p}<0.05)$.
BMI: Body Mass Index; BP: Blood pressure; C-RP: C reactive protein (Positive results if the levels had caused severe inflammation or Negative if C-RP level was under the inflammation standards); CK: Creatine kinase; LDH: Lactate dehydrogenase. Different letters indicate differences $(p \leq 0.05)$ between groups.
TABLE 1 - Rest values of all variables are presented and compared between the presence or not of type 2 diabetes mellitus $(n=40)$.

\begin{tabular}{lcccc}
\hline & \multicolumn{2}{c}{ RE - 60\% 1RM } & \multicolumn{2}{c}{ RE - 75\% 1RM } \\
\cline { 2 - 5 } & Non Diabetic (n=10) & Diabetic (n=10) & Non Diabetic (n=10) & Diabetic (n=10) \\
\hline Age (years) & $49 \pm 8.5$ & $54.1 \pm 6.9$ & $45 \pm 3.4$ & $54.1 \pm 10.5$ \\
BMI (kg/m ) & $27.1 \pm 2.8^{\mathrm{a}}$ & $32.6 \pm 3.2^{\mathrm{b}}$ & $27.6 \pm 2.9^{\mathrm{a}, \mathrm{c}}$ & $32.3 \pm 4.1^{\mathrm{b}, \mathrm{d}}$ \\
Glycemia (mg/dL) & $104.1 \pm 11.6^{\mathrm{a}}$ & $127.4 \pm 14.6^{\mathrm{b}}$ & $102.9 \pm 10.9^{\mathrm{a}, \mathrm{c}}$ & $135.6 \pm 11.7^{\mathrm{b}, \mathrm{d}}$ \\
Heart Rate (bpm) & $73.2 \pm 11$ & $77.0 \pm 8.5$ & $77.6 \pm 11$ & $77.0 \pm 5.9$ \\
Systolic BP (mmHg) & $118.2 \pm 8.9^{\mathrm{a}}$ & $141.1 \pm 8.2^{\mathrm{b}}$ & $122.3 \pm 8.3^{\mathrm{a}, \mathrm{c}}$ & $147.9 \pm 15^{\mathrm{b}, \mathrm{d}}$ \\
Diastolic BP (mmHg) & $79.1 \pm 3.8^{\mathrm{a}}$ & $82.3 \pm 2.7^{\mathrm{b}}$ & $78.6 \pm 5.1^{\mathrm{a}, \mathrm{c}}$ & $82.6 \pm 2.4^{\mathrm{b}, \mathrm{d}}$ \\
Testosterone (ng/dL) & $308.6 \pm 122.8$ & $299.3 \pm 75.1$ & $366.2 \pm 64.5$ & $317.2 \pm 52.2$ \\
Cortisol (ug/dL) & $19.7 \pm 3.8$ & $16.4 \pm 2.9$ & $22.1 \pm 4.9$ & $17.3 \pm 1.5$ \\
C-RP* & Negative & Negative & Negative & Negative \\
CK (U/mL) & $99.1 \pm 40.8$ & $95.2 \pm 22.2$ & $104.1 \pm 21.7$ & $98 \pm 27.2$ \\
LDH (U/L) & $238.8 \pm 36.2$ & $280.9 \pm 65.1$ & $221.9 \pm 23.7$ & $294.9 \pm 41.6$ \\
\hline
\end{tabular}


A

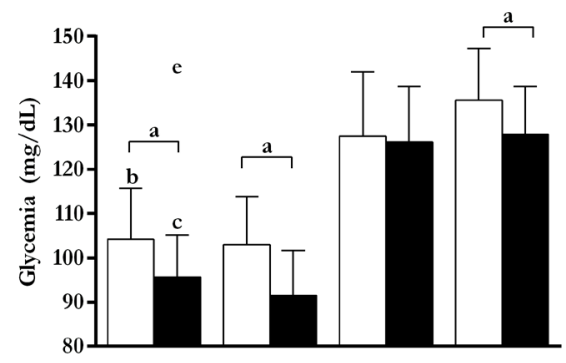

C

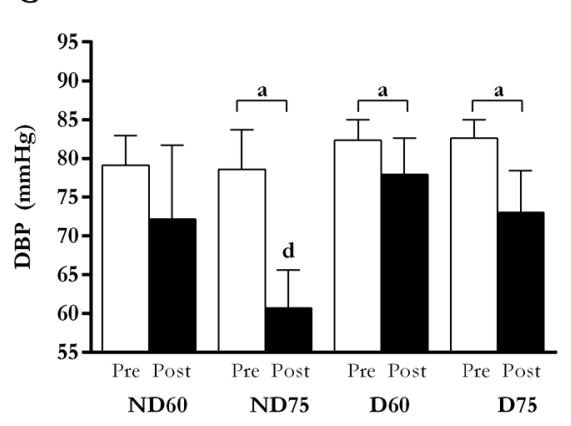

B
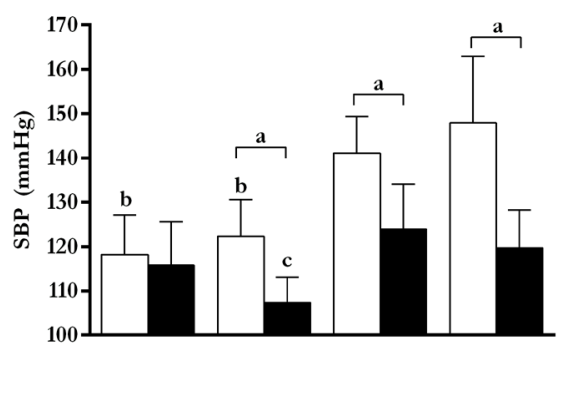

${ }^{a} \mathrm{p}<0.05$ in relation to each other; ${ }^{\mathrm{b}} \mathrm{p}<0.05$ in relation to Pre from both $\mathrm{D}$ groups; ${ }^{\mathrm{c}} \mathrm{p}<0.05$ in relation to Post from both D groups; ${ }^{\mathrm{d}} \mathrm{p}<0.05$ in relation to Post from other groups.

than pre-RE for both groups and intensities, except for ND60.

$\mathrm{CK}$ and $\mathrm{LDH}$ presented significant changes in different moments and groups but is relevant to highlight the significant increase $(\mathrm{p}<0.05)$ for those variables after RE at 75\%1RM, (FIGURES $3 \mathrm{~A}$ and $\mathrm{B})$. (FIGURE $2 \mathrm{~B}$ ). The ratio T:C post-RE was higher
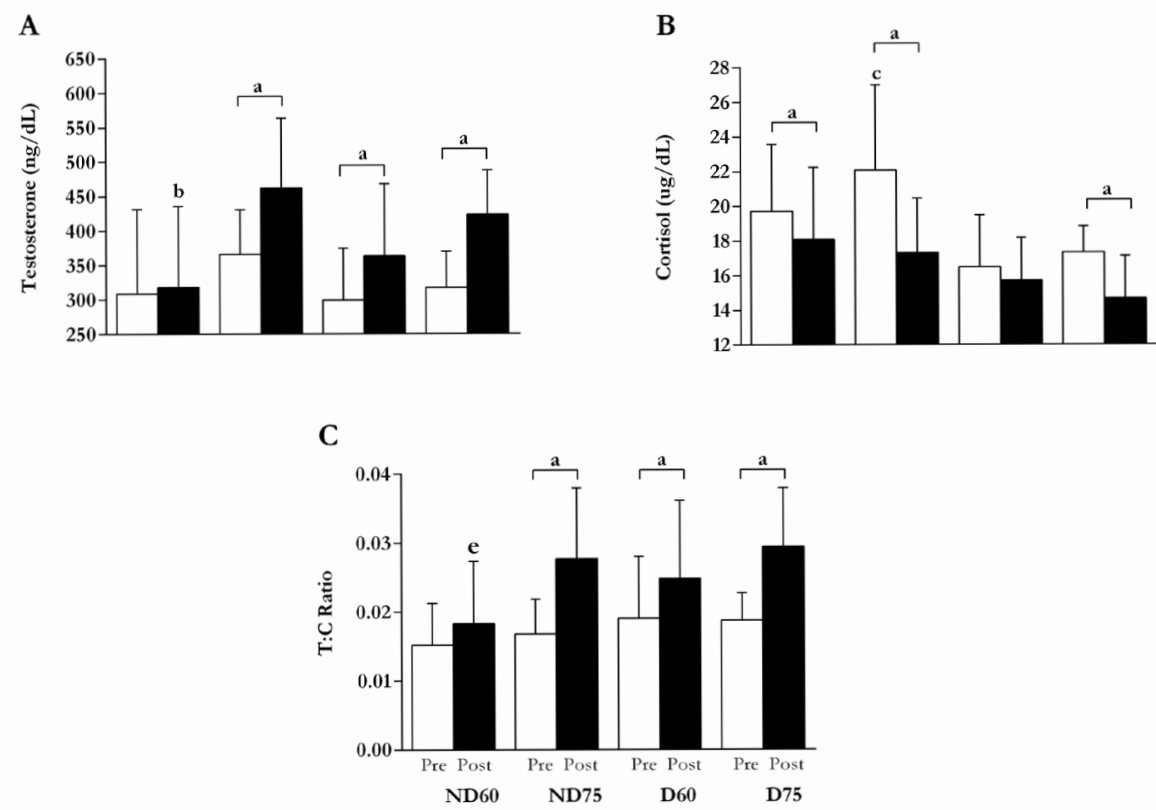
significant elevation $(\mathrm{p}<0.05)$ of the testosterone sessions resulted in increasing of the testosterone $(\mathrm{p}<0.05)$ for D groups (FIGURE 2A). There was a reduction $(\mathrm{p}<0.05)$ of the cortisol, but not to D60

FIGURE 2 -Testosterone (A), cortisol (B) concentrations and ratio T:C (C) for all groups pre- and post-resistance exercise sessions. 
${ }^{a} \mathrm{p}<0.05$ in relation to each other; b $\mathrm{p}<0.05$ in relation to Post from ND75 and D75; ${ }^{\mathrm{p}} \mathrm{p}<0.05$ in relation to Pre from both $\mathrm{D}$ groups; ${ }^{\mathrm{d}} \mathrm{p}<0.05$ in relation to Pre from both ND groups; ${ }^{\mathrm{e}} \mathrm{p}<0.05$ in relation to Post from D75.
A

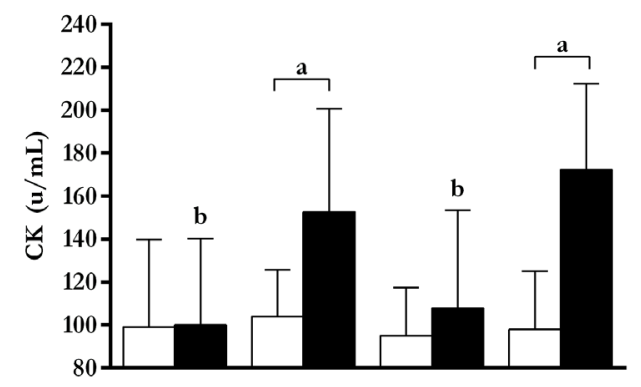

B

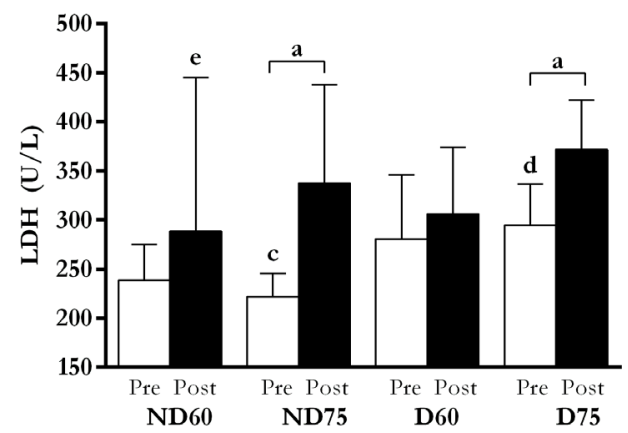

FIGURE 3 -Creatine kinase (A) and lactate dehydrogenase (B) for all groups pre- and post-resistance exercise sessions.

\section{Discussion}

The main finding in this study was the fact of highest moderate intensity (75\%1RM) showed a better glucose uptake from the diabetic group. In addition, independently of RE intensity, the moderate exercises sessions were capable to reduce BP of diabetic groups with a notable tendency to a better reduction in the higher RE intensity. The hormonal response after exercises was suitable for a good exercise recovery, mainly for exercise performed at 75\%1RM, which resulted in an elevated indirect marker of muscle damage.

In the present study, the diabetics presented higher BMI, glycemia, SBP, and DPB than nondiabetic groups. Normally, diabetic individuals present many physiological dysfunctions such as cardiovascular disease and hypertension, what increase morbidity and mortality ${ }^{22}$. T2D is associated with the gain of fat mass and can generate obesity, particularly central obesity. This may lead to an increased release of free fatty acids due to its high sensitivity through the action of catecholamines, which can produce a greater vasoconstriction and fluid retention, leading to hypertension ${ }^{23,24}$. Moreover, it is known that obese individuals usually have more difficulty to move around, join mobility reduction, and/or difficult to execute simple tasks of daily life such as climbing stairs $^{25}$. The lack of regular physical activity in these pathological groups during their lives ${ }^{26}$ could have contributed to a worse quality of strength, higher BMI (obese) and BP levels observed in the present study (TABLE 1).

The regular practice of physical exercise, or even a single exercise session, is one of the most nonpharmacological treatments used to prevent and/ or reduce the advancement of hypertension and $\mathrm{T} 2 \mathrm{D}^{27,28}$. In this sense, one useful method that can be used to achieve the benefits for diabetic subjects is the RE since it promotes cardio-metabolic and neuromuscular adaptations ${ }^{29}$. In this context, stimulation and a very good prescription of the physical exercise are necessary to this population. The knowledge about the best moderate RE intensity that should be prescribed to improve physiological benefits can help to control blood glucose and BP levels.

Resistance exercise at 75\% 1RM performed by $\mathrm{D}$ group resulted in a significant reduction of its glycemic level. This result was in agreement with previous findings where exercise with higher intensity was better to control blood glucose level ${ }^{30,31}$, even existing another study showing that regardless of intensity (low or moderate), an acute blood glucose uptake will be observed after a resistance circuit exercis ${ }^{32}$. This data of the present study indicated that with more intensive stimulation (until the upper limit of the moderate intensity), more blood glucose uptake is obtained, corroborating others studies ${ }^{31,32}$.

Some hormones such as catecholamine, cortisol, and glucagon increase as the exercise intensity raised, what may result in an increase of the liver glycolysis, increasing the blood glucose availability ${ }^{33}$. However, even with this hormonal pattern, the high-moderate exercise intensity performed at $75 \% 1 \mathrm{RM}$ resulted in an adequate stimulus for increasing blood glucose 
uptake by the active muscles, resulting in a reduction of BP after exercise. Moreover, the cortisol levels after exercise performed at 75\% 1RM presented a significant reduction.

The insulin sensibility increases after exercise due to an improvement of PI3-K and AKT activity, among others possibilities such as interleukins activation $^{34}$. The high-moderate intensity probably resulted in more vigorous muscle contraction than low-moderate intensity, resulting in a higher blood glucose uptake as observed in the present study, what can explain that the muscle is considered the major body tissue capable to use blood glucose to generate biological energy ${ }^{30,35}$.

$\mathrm{BP}$ level is associated with many health risk factors and diseases including $\mathrm{T} 2 \mathrm{D}^{36}$. The exercise sessions applied in the present study resulted in acute BP benefits for all groups (FIGURE 2) and $\mathrm{PEH}$ has been observed in normotensive, hypertensive $\mathrm{e}^{37,38}$, and diabetic individuals being well described in the literature ${ }^{35,36,39}$.

Acute resistance circuit exercise is better than aerobic exercise to control BP during the $24 \mathrm{~h}$ after exercise in diabetic subjects ${ }^{6}$, an acute circuit of RE is better than aerobic exercise to control BP during the $24 \mathrm{~h}$ after exercise in diabetic subjects.

Asano et al. ${ }^{22}$ in a review study suggest as the exercise intensity increases it is possible to observe a higher PEH. Basically, the studies reviewed by these authors were conducted utilizing exercises at light and/or moderate intensities. A greater PEH for the highest intensities when analyzed light and moderate intensities, independently if the exercise was aerobic or resistance ${ }^{31,39,40}$. Part of these results can explained by the nitric oxide levels since a highintensity exercise protocol is capable to induce nitric oxide release in hypertensive older women ${ }^{41}$.

On the other hand, Мотта et al. ${ }^{42}$ did not observe significant PEH for diabetics, suggesting a possible positive relationship between $\mathrm{PEH}$ and plasma kallikrein activity, since there was less kallikrein activity for diabetics. However, the exercise model was not RE and it was performed $10 \%$ below of their anaerobic threshold. According to Dutra et al. ${ }^{43}$, the PEH can influenced by many variables, including the exercise intensity.

In the present study, the acute exercises performed at $75 \%$ and $60 \% 1 \mathrm{RM}$ were capable to induce $\mathrm{PEH}$ in $\mathrm{D}$ groups with a better BP kinesis after exercise performed at 75\% 1RM, which is considered a moderate exercise since a few relevant scientific studies have shown that the high RE intensity starts at $80 \% 1 \mathrm{RM}^{37,44}$. The ACSM suggests $\mathrm{RE}$ at $60 \%$ 1RM for hypertensive and diabetic individuals, and American Heart Association describe it should be over $60 \%$ of the maximum intensity ${ }^{14}$.

As observed in the present study, good results in both moderate exercise intensities used were found, but the results revealed to be better at 75\% 1RM. A new division or subdivision in moderate RE could be proposed and further studies to confirm our findings are necessary to assess whether the changes in RE intensity affects the results.

It is important to note that the total volume of the resistance exercise at $60 \%$ and $75 \% 1 \mathrm{RM}$ were not differed $(p>0.05)$ between the four groups (ND60, ND75, D60, D75), revealing the effects of intensity on metabolic and hemodynamic variables. Similar to the present study, an acute RE session of higher intensity followed by an oral glucose tolerance presented lower glycemia and insulinemia than lower intensity, even with a similar total volume of exercise sessions ${ }^{45}$.

In relation to hormonal kinetics, KIM et al. ${ }^{46}$ demonstrated that healthy individuals who performed a high-intensity RE presented elevated testosterone levels as observed in our present study, even in different intensities (FIGURE 3A). However, it is also described that testosterone can be reduced in $\mathrm{RE}^{10}$. Our results revealed an increase of the testosterone plasma level in D groups after both moderate intensities. Higher testosterone levels in response to RE is associated with a necessary adaptation of the organism, especially at an increased intensity ${ }^{47}$.

Cortisol levels were significantly reduced in ND groups and in D group who performed RE at $75 \%$ 1RM (FIGURE 3B). Cortisol reduction was also observed in the elderly population after performing $\mathrm{RE}$ at $50 \%$ and $80 \% 1 \mathrm{RM}^{48}$, as reported by UCHIDA et al. ${ }^{49}$ in women.

Our results reveal a positive relation of T:C ratio in moderate $\mathrm{RE}$ at both intensities for $\mathrm{D}$ groups, indicating anabolic parameter was immediately active. It might be higher at 75\%1RM to help to repair the physiological stress observed through a higher muscle damage at this intensity, even they were not obtaining at their peak level after exercise. $\mathrm{T}$ :C ratio was increased in our study, showing a prevalence of anabolic conditions over catabolic, corroborating the data found by UCHIDA et al. ${ }^{49}$.

T2D pathology influences and promotes the increase of serum markers of muscle damage ${ }^{50}$ for rest values. In the present study, there was only 
concomitant and significant increase of $\mathrm{CK}$ and $\mathrm{LDH}$ in higher amounts of moderate RE, revealing a greater muscle damage in T2D hypertensive individuals at $75 \% 1 \mathrm{RM}$. It is possible that the greatest amount of CK found after RE was due to a constant trial of the organism to restore the energy reserves during the exercise protocols ${ }^{9,51,52}$. The largest amount of LDH could be justified by an increase of the anaerobic work, disposing of more lactate in blood, once the exercise performed at a higher intensity can activate three times more $\mathrm{LDH}$, contributing to a possible greater expression of glucose transporters and improving, on this way, insulin sensitivity ${ }^{53,54}$.

The analysis of muscle damage associated with the elevation or the lowering of inflammatory proteins, such as C-RP, may help to diagnose the best type of RE to be developed. The C-RP is release in greater quantities in the body when there is a proinflammatory activity in progress that can be caused by bacteria, viruses or simple metabolic stress provided by physical activity, for example $e^{55,56}$. The acute RE at any level of moderate intensity in this study was not able to generate a severe pro-inflammatory activity to increase beyond the point of reference standards C-RP levels. This result indicates that there is no contraindication for using moderate $\mathrm{RE}$ at $60 \%$ or $75 \% 1 \mathrm{RM}$ in an RE program for diabetics or non-diabetics.

Physiological changes at 75\% 1RM occurred more than in 60\% $1 \mathrm{RM}$ to diabetics and healthy people in the present study. In spite of that, moderate training zone, which goes from $60 \%$ to
$79 \%$ of the maximum intensity, could divided into two or more sub sessions such as lower moderate and upper moderate training zones. Further studies, diagnosing physiological responses at $60 \%$, 65\%, 70\%, 75\% and 79\% 1RM, for example, would give us a better idea about the differences in these physiological changes at the moderate training zone. Our data reinforce the importance of $\mathrm{RE}$ as a non-pharmacological treatment for T2D, mainly because of the improvement in the blood glucose uptake and the BP reduction after one single session of RE at 75\%1RM.

The moderate resistance exercise at 75\% 1RM promotes better blood glucose uptake and BP management in diabetic subjects. Moderate exercise at $60 \%$ or $75 \% 1 \mathrm{RM}$ is capable to reduce $\mathrm{BP}$ after RE to diabetic and hypertensive subjects. The testosterone and cortisol hormones after these $\mathrm{RE}$ in moderate intensities suggest the existence of an appropriated exercise recovery, especially after $75 \% 1 \mathrm{RM}$ that results in higher values of indirect muscle damage markers. There is no acute increase in C-RP after moderate RE intensities at 60 and 75\% 1RM.

Acute RE brings benefits to diabetics who are hypertensive. Thus, higher intensity of RE targeting over $75 \% 1 \mathrm{RM}$ can performed without risk to the individual. Besides, the results found in this study, it is always necessary that diabetic hypertensive individuals to be supervised during all period of their training sessions for safety reasons. Acute RE at $60 \%$ or $75 \%$ of $1 \mathrm{RM}$ can be used as an extra tool to help the management of both pathologic conditions combined (diabetes and hypertension).

\section{Resumo}

Exercício resistido de intensidade moderada/alta é melhor para reduzir a glicose sanguínea e pressão arterial em indivíduos diabéticos na meia-idade

A principal característica do diabetes tipo 2 (DM2) é a resistência à insulina. A hipertensão é uma comorbidade relacionada à DM2. 0 exercício resistido (ER) é uma importante ferramenta não-farmacológica para o controle da glicemia e pressão arterial (PA), mas não existe consenso sobre os efeitos agudos. 0 objetivo do estudo foi avaliar o efeito agudo fisiológico após duas sessões de ER em diferentes intensidades em indivíduos de meia-idade hipertensos e com DM2. Foram 40 homens de meia-idade (20 não-diabéticos; 20 diabéticos), submetidos a um protocolo de exercícios de mesmo volume a 60\% ou 75\% do teste de repetição máxima (1RM), consistindo em: supino reto, triceps no pulley, remada no aparelho, rosca direta com barra, elevação lateral com halteres e agachamento com barra. As alterações fisiológicas foram avaliadas através da PA, glicemia, creatina quinase, lactato desidrogenase, proteína C-reativa (PCR), testosterona e cortisol. Para os não-diabéticos, ambas intensidades promoveram captação de glicose sanguínea (8,2\% a 11,1\%, 
$p<0,05)$, e apenas a sessão 75\%1RM induziu captação de glicose sanguínea em 5,7\% nos diabéticos. A hipotensão pós-exercício foi significativa após ER a 75\%1RM na PA sistólica (PAS), e após ambas intensidades na PA diastólica (PAD) em não-diabéticos, enquanto a PAS e PAD reduziram após ambas intensidades nos diabéticos. ER a 75\%1RM resultou em melhor captação de glicose sanguínea, e ambas intensidades reduziram a PA nos diabéticos. Após 75\%1RM, houve maiores danos musculares indiretos. As alterações nos hormônios, PCR e marcadores indiretos de dano muscular indicaram adequada recuperação anabólica aguda sem inflamação significativa em ambas intensidades. 0 ER agudo a 60\%1RM ou 75\%1RM pode ser usado como uma ferramenta extra para gerenciar ambas condições patológicas.

PalavRas-Chave: Diabetes Mellitus Tipo 2; Hipertensão; Exercício Resistido; Saúde.

\section{References}

1. Ogurtsova K, da Rocha Fernandes JD, Huang Y, Linnenkamp U, Guariguata L, Cho NH, et al. IDF Diabetes Atlas: Global estimates for the prevalence of diabetes for 2015 and 2040. Diabetes Res Clin Pract. 2017;128:40-50.

2. Snel M, Gastaldelli A, Ouwens DM, Hesselink MK, Schaart G, Buzzigoli E, et al. Effects of adding exercise to a 16week very low-calorie diet in obese, insulin-dependent type 2 diabetes mellitus patients. J Clin Endocrinol Metab. 2012;97(7):2512-20.

3. Suh DC, Kim CM, Choi IS, Plauschinat CA, Barone JA. Trends in blood pressure control and treatment among type 2 diabetes with comorbid hypertension in the United States: 1988-2004. J Hypertens. 2009;27(9):1908-16.

4. Roden M. Exercise in type 2 diabetes: to resist or to endure? Diabetologia. 2012;55(5):1235-9.

5. Maiorana AJ, Naylor LH, Exterkate A, Swart A, Thijssen DH, Lam K, et al. The impact of exercise training on conduit artery wall thickness and remodeling in chronic heart failure patients. Hypertension. 2011;57(1):56-62.

6. Morais PK, Campbell CS, Sales MM, Motta DF, Moreira SR, Cunha VN, et al. Acute resistance exercise is more effective than aerobic exercise for 24h blood pressure control in type 2 diabetics. Diabetes Metab. 2011;37(2):112-7.

7. Tompkins CL, Soros A, Sothern MS, Vargas A. Effects of physical activity on diabetes management and lowering risk for type 2 diabetes. J Health Educ. 2009;40(5):286-90.

8. Roma MFB, Busse AL, Betoni RA, Melo ACd, Kong J, Santarem JM, et al. Effects of resistance training and aerobic exercise in elderly people concerning physical fitness and ability: a prospective clinical trial. Einstein. 2013;11(2):153-7.

9. Santos WOC, Brito CJ, Júnior EAP, Valido CN, Mendes EL, Nunes MAP, et al. Cryotherapy post-training reduces muscle damage markers in jiu-jitsu fighters. J Hum Sport Exerc. 2012;7(3):629-38.

10. Cheung KK, Luk AO, So WY, Ma RC, Kong AP, Chow FC, et al. Testosterone level in men with type 2 diabetes mellitus and related metabolic effects: A review of current evidence. J Diabetes Investig. 2015;6(2):112-23.

11. Kraemer WJ, Ratamess NA. Hormonal responses and adaptations to resistance exercise and training. Sports Med. 2005;35(4):339-61.

12. Adams OP. The impact of brief high-intensity exercise on blood glucose levels. Diabetes Metab Syndr Obes. 2013;6:11322.

13. Haskell WL, Lee IM, Pate RR, Powell KE, Blair SN, Franklin BA, et al. Physical activity and public health: updated recommendation for adults from the American College of Sports Medicine and the American Heart Association. Med Sci Sports Exerc. 2007;39(8):1423-34.

14. de Freitas Brito A, de Oliveira CVC, do Socorro Brasileiro-Santos M, da Cruz Santos A. Resistance exercise with different volumes: blood pressure response and forearm blood flow in the hypertensive elderly. Clin Interv Aging. 2014;12:2151-8.

15. Gonzalez-Badillo JJ, Gorostiaga EM, Arellano R, Izquierdo M. Moderate resistance training volume produces more favorable strength gains than high or low volumes during a short-term training cycle. J Strength Cond Res. 2005;19(3):689-97.

16. Colberg SR, Albright AL, Blissmer BJ, Braun B, Chasan-Taber L, Fernhall B, et al. Exercise and type 2 diabetes: American College of Sports Medicine and the American Diabetes Association: joint position statement. Exercise and type 2 diabetes. Med Sci Sports Exerc. 2010;42(12):2282-303.

17. Brown LE, Weir JP. ASEP Procedures recomendation I: Accurate assessment of muscular strenght and power. JEPonline. 
2001;4(3):1-21.

18. Koch AJ, Pereira R, Machado M. The creatine kinase response to resistance exercise. J Musculoskelet Neuronal Interact. 2014;14(1):68-77.

19. Chobanian AV, Bakris GL, Black HR, Cushman WC, Green LA, Izzo JL, et al. The Seventh Report of the Joint National Committee on Prevention, Detection, Evaluation, and Treatment of High Blood Pressure: the JNC 7 report. JAMA. 2003;289(19):2560-72.

20. Pescatello LS, Franklin BA, Fagard R, Farquhar WB, Kelley GA, Ray CA, et al. Exercise and Hypertension. Med Sci Sports Exerc. 2004;36(3):533-53.

21. Kelly AS, Bergenstal RM, Gonzalez-Campoy JM, Katz H, Bank AJ. Effects of exenatide vs. metformin on endothelial function in obese patients with pre-diabetes: a randomized trial. Cardiovasc Diabetol. 2012;11:64.

22. Asano RY, Sales MM, Browne RAV, Nova JFV, Moraes HJCJ, Moraes MR, et al. Acute effects of physical exercise in type 2 diabetes: A review. World J Diabetes. 2014;5(5):659-665. doi:10.4239/wjd.v5.i5.659.

23. Ferrao FM, Lara LS, Lowe J. Renin-angiotensin system in the kidney: What is new? World J Nephrol. 2014;3(3):6476.

24. Sullivan PW, Ghushchyan V, Ben-Joseph RH. The effect of obesity and cardiometabolic risk factors on expenditures and productivity in the United States. Obesity (Silver Spring). 2008;16(9):2155-62.

25. Akpinar TS, Tayfur M, Tufan F, Sahinkaya T, Kose M, Ozsenel EB, et al. Uncomplicated diabetes does not accelerate age-related sarcopenia. Aging Male. 2014;17(4):205-10.

26. Mendes R, Sousa N, Almeida A, Subtil P, Guedes-Marques F, Reis VM, et al. Exercise prescription for patients with type 2 diabetes_a synthesis of international recommendations: narrative review. Br J Sports Med. 2015;50(22):137981.

27. Mendes TAB, Goldbaum M, Segri NJ, Barros MBA, César CLG, Carandina L. Factors associated with the prevalence of hypertension and control practices among elderly residents of São Paulo city, Brazil. Cad Saude Publica. 2013;29(11):2275-86.

28. Cavalcante PAM, Rica RL, Evangelista AL, Serra AJ, Figueira Jr A, Pontes Jr FL, et al. Effects of exercise intensity on postexercise hypotension after resistance training session in overweight hypertensive patients. Clin interv Aging. 2015;10:1487.

29. Cadore EL, Pinto RS, Bottaro M, Izquierdo M. Strength and endurance training prescription in healthy and frail elderly. Aging Dis. 2014;5(3):183-95.

30. van Dijk J-W, Manders R, Tummers K, Bonomi A, Stehouwer C, Hartgens F, et al. Both resistance-and endurance-type exercise reduce the prevalence of hyperglycaemia in individuals with impaired glucose tolerance and in insulin-treated and non-insulin-treated type 2 diabetic patients. Diabetologia. 2012;55(5):1273-82.

31. Hiyane WC, de Sousa MV, Moreira SR, do Valle G, de Oliveira RJ, Arsa G, et al. Blood glucose responses of type-2 diabetics during and after exercise performed at intensities above and below anaerobic threshold. Brazilian J Kinanthrop Human Perfor. 2008;10(1):8-11.

32. Moreira SR, Simoes GC, Moraes JF, Motta DF, Campbell CS, Simoes HG. Blood glucose control for individuals with type-2 diabetes: acute effects of resistance exercise of lower cardiovascular-metabolic stress. J Strength Cond Res. 2012;26(10):2806-11.

33. Canali ES, Kruel LFM. Respostas hormonais ao exercício. Rev Paul Educ Fís. 2001;15(2):141-53.

34. Folli F, Saad M, Backer JM, Kahn CR. Insulin stimulation of phosphatidylinositol 3-kinase activity and association with insulin receptor substrate 1 in liver and muscle of the intact rat. J Biol Chem. 1992;267(31):22171-7.

35. Arsa G, Lima L, Almeida S, Moreira SR, Campbell CSG, Simóes HG. Diabetes Mellitus tipo 2: Aspectos fisiológicos, genéticos e formas de exercício físico para seu controle. Rev Bras Cineantropom Desempenho Hum. 2009;11(1):10311.

36. Costanzi CB, Halpern R, Rech RR, Bergmann MLdA, Alli LR, Mattos APd. Associated factors in high blood pressure among schoolchildren in a middle size city, southern Brazil. J Pediatr. 2009;85(4):335-40.

37. Rezk CC, Marrache RC, Tinucci T, Mion D, Forjaz CL. Post-resistance exercise hypotension, hemodynamics, and heart rate variability: influence of exercise intensity. Eur J Appl Physiol. 2006;98(1):105-12.

38. Chen CY, Bonham AC. Postexercise hypotension: central mechanisms. Exerc Sport Sci Rev. 2010;38(3):122-7.

39. Sales MM, Russo P, Moreira SR, Santana H, Moraes JF, Asano RY, et al. Resistance exercise elicits acute blood pressure reduction in type 2 diabetics. J Exerc Physiol Online. 2012;15:98-109.

40. Simoes GC, Moreira SR, Kushnick MR, Simoes HG, Campbell CS. Postresistance exercise blood pressure reduction is 
influenced by exercise intensity in type-2 diabetic and nondiabetic individuals. J Strength Cond Res. 2010;24(5):127784.

41. Santana HA, Moreira SR, Asano RY, Sales MM, Cordova C, Campbell CS, et al. Exercise intensity modulates nitric oxide and blood pressure responses in hypertensive older women. Aging Clin Exp Res. 2013;25(1):43-8.

42. Motta DF, Lima LC, Arsa G, Russo PS, Sales MM, Moreira SR, et al. Effect of type 2 diabetes on plasma kallikrein activity after physical exercise and its relationship to post-exercise hypotension. Diabetes Metab. 2010;36(5):363-8.

43. Dutra MT, Lima RM, Mota MR, de Oliveira PFA, Veloso JHCL. Hipotensão pós-exercício resistido: uma revisão da literatura. . Rev Educ Fis/UEM. 2013;24(1):145-57.

44. Pollock ML, Franklin BA, Balady GJ, Chaitman BL, Fleg JL, Fletcher B, et al. AHA Science Advisory. Resistance exercise in individuals with and without cardiovascular disease: benefits, rationale, safety, and prescription: An advisory from the Committee on Exercise, Rehabilitation, and Prevention, Council on Clinical Cardiology, American Heart Association; Position paper endorsed by the American College of Sports Medicine. Circulation. 2000;101(7):828-33.

45. Miller AD, Ruby BC, Laskin JJ, Gaskill SE. Effects of high intensity / low volume and low intensity / high volume isokinetic resistance exercise on postexercise glucose tolerance. J Strength Cond Res. 2007;21(2):330-5.

46. Kim HH, Kim YJ, Lee SY, Jeong DW, Lee JG, Yi YH, et al. Interactive effects of an isocaloric high-protein diet and resistance exercise on body composition, ghrelin, and metabolic and hormonal parameters in untrained young men: A randomized clinical trial. J Diabetes Investig. 2014;5(2):242-7.

47. Sgro P, Romanelli F, Felici F, Sansone M, Bianchini S, Buzzachera CF, et al. Testosterone responses to standardized short-term sub-maximal and maximal endurance exercises: issues on the dynamic adaptive role of the hypothalamic-pituitary-testicular axis. J Endocrinol Invest. 2014;37(1):13-24.

48. Oliveira RJ, Lima RM, Gentil P, Simóes HG, Ávila WRdM, Silva RW, et al. Acute hormonal responses to different intensities of resistance exercises in older women. Rev Bras Med Esporte. 2008;14(4):367-71.

49. Uchida MC, Bacurau RFP, Navarro F, Pontes Jr FL, Tessuti VD, Moreau RL, et al. Alteration of testosterone: cortisol ratio induced by resistance training in women. Rev Bras Med Esporte. 2004;10(3):165-8.

50. Passarella S, de Bari L, Valenti D, Pizzuto R, Paventi G, Atlante A. Mitochondria and L-lactate metabolism. FEBS Lett. 2008;582(25-26):3569-76.

51. Ostler JE, Maurya SK, Dials J, Roof SR, Devor ST, Ziolo MT, et al. Effects of insulin resistance on skeletal muscle growth and exercise capacity in type 2 diabetic mouse models. Am J Physiol Endocrinol Metab. 2014;306(6):E592605 .

52. Christ CY, Hunt D, Hancock J, Garcia-Macedo R, Mandarino LJ, Ivy JL. Exercise training improves muscle insulin resistance but not insulin receptor signaling in obese Zucker rats. J Appl Physiol. 2002;92(2):736-44.

53. Goodwin ML, Harris JE, Hernandez A, Gladden LB. Blood lactate measurements and analysis during exercise: a guide for clinicians. J Diabetes Sci Technol. 2007;1(4):558-69.

54. Billat VL, Sirvent P, Py G, Koralsztein JP, Mercier J. The concept of maximal lactate steady state: a bridge between biochemistry, physiology and sport science. Sports Med. 2003;33(6):407-26.

55. Dunstan DW, Zimmet PZ, Welborn TA, De Courten MP, Cameron AJ, Sicree RA, et al. The rising prevalence of diabetes and impaired glucose tolerance: the Australian Diabetes, Obesity and Lifestyle Study. Diabetes Care. 2002;25(5):82934.

56. American Diabetes A. Standards of medical care in diabetes--2014. Diabetes Care. 2014;37(Suppl. 1):S14-80.

\begin{tabular}{r|r} 
& \\
CorResPonding AUTHoR: & \\
Gisela Arsa & \\
Avenida Fernando Corrêa da Costa, sn - Boa Esperança & Submitted: 20/03/2017 \\
Cuiabá - MT - BRAZIL & 1st. Review: 06/07/2017 \\
CEP: 78060900 & 2nd. Review: 15/09/2017 \\
E-mail: gisarsa@gmail.com & Accepted: 28/07/2017
\end{tabular}

